\title{
Discursos filosóficos do reconhecimento
}

\author{
Philosophical discourses of recognition
}

\author{
Giovani A. Saavedra \\ Emil A. Sobottka*
}

\begin{abstract}
Resumo: O presente texto procura explorar o percurso e o desenvolvimento do conceito de reconhecimento nos debates recentes. O objetivo principal é explorar a polissemia do conceito para mostrar toda a complexidade da discussão em torno do tema. Esta tarefa é realizada a partir de uma reconstrução de dois debates contemporâneos: entre Taylor e Habermas e entre Fraser e Honneth, em diálogo com a perspectiva da teoria do reconhecimento de Paul Ricoeur.
\end{abstract}

Palavras-chave: Reconhecimento; Liberalismo; Minorias; Redistribuição

\begin{abstract}
This paper seeks to explore the trajectory and the development of the concept of recognition in recent debates. Having in view the complexity of this topic, our main purpose is the exploration of the concept's polysemy. This task will be accomplished starting with the reconstruction of two contemporary debates: the first one between Taylor and Habermas and the second one between Fraser and Honneth, dialoging with Paul Ricouer's recognition theory.
\end{abstract}

Keywords: Recognition; Liberalism; Minorities; Redistribution

\section{Introdução}

Reconhecimento se tornou um conceito central da teoria social contemporânea. O presente texto procura explorar o percurso e o desenvolvimento deste conceito explorando a sua polissemia intrínseca com objetivo de mostrar toda a complexidade da discussão em torno do tema. O primeiro estágio deste percurso pode ser encontrado no debate entre Taylor e Habermas. A

* Giovani A. Saavedra é doutor em Filosofia e em Direito pela Universidade de Frankfurt. $<$ giovani.saavedra@pucrs.br>. Emil A. Sobottka é doutor em Sociologia pela Universidade de Muenster.<sobottka@pucrs.br>. Ambos são professores nos programas de pós-graduação em Ciências Criminais e em Ciências Sociais da Pucrs, em Porto Alegre, RS, Brasil.

\begin{tabular}{|c|c|c|c|c|c|}
\hline Civitas & Porto Alegre & v. 9 & n. 3 & p. 386-401 & set.-dez. 2009 \\
\hline
\end{tabular}


partir de uma análise deste debate pode-se explorar todas as possibilidades de desenvolvimento do conceito de reconhecimento como identidade ou autenticidade. Num segundo estágio deste percurso, o debate entre Fraser e Honneth foca nos aspectos políticos e éticos do conceito. Estes dois debates serão analisados a partir da teoria do reconhecimento de Paul Ricoeur, principalmente porque o autor pode ser considerado talvez o primeiro autor que procurou, a partir do conceito de reconhecimento, reler todas as principais categorias da filosofia tradicional.

\section{Reconhecimento e identidade no estado democrático}

Em seu texto A política do reconhecimento, Charles Taylor (2000) discute a questão do reconhecimento das culturas e sua relação com a identidade no contexto das lutas por políticas destinadas a garantir a sobrevivência de culturas específicas. O pano de fundo de sua discussão são disputas dos canadenses aborígenes e de fala francesa com seus concidadãos de origem anglo-saxã. $\mathrm{Na}$ província de Quebec, de maioria francófona, haviam sido introduzidas políticas cujo objetivo era preservar o modo de vida da população ali majoritária e que era percebido como ameaçado pela cultura anglo-saxã, majoritária no país como um todo. Entre essas medidas, Taylor destaca: obrigação de que francófonos e imigrantes coloquem os filhos em escolas de fala francesa; a obrigação de que o francês fosse a língua oficial de comunicação em empresas com mais de 50 funcionários; e a obrigatoriedade do uso do idioma francês em placas de sinalização. A pretensão do autor transcende em muito esta disputa local, pois ele pretende analisar a possibilidade mais ampla de sociedades democráticas liberais reconhecerem diferenças constitutivas de identidades específicas em seu interior.

Taylor descreve a identidade como a compreensão de quem se é, descoberta de sua própria diferença ou autenticidade. Essa identidade individualizada vem, segundo o autor, conjugada ao ideal de ser fiel ao modo próprio de ser de cada indivíduo ou coletividade, por ele designado como ideal de autenticidade. Para o autor, a identidade seria moldada em boa medida pelo reconhecimento por parte de outros, em relações dialógicas. A ausência do reconhecimento ou um reconhecimento errôneo, quando internalizado, por seu turno, pode oprimir e aprisionar em modalidades falsas ou redutoras de identidade, tornando as pessoas inautênticas. Por conseguinte, o autor procura formular uma base teórica capaz de dar sustentação a reivindicações de reconhecimento dentro de um estado democrático de direito de orientação liberal. Para dar conta desse objetivo, ele argumenta que concepções de reconhecimento igual formal 
são insuficientes para assegurar a sobrevivência de culturas específicas; por isso torna-se necessária uma nova concepção da relação entre igualdade e diversidade. Ponto de partida desse empreendimento é reconstituir a trajetória do surgimento do discurso sobre reconhecimento e identidade como resultado do colapso da noção hierárquica de honra e sua substituição pela noção igualitária de dignidade.

$\mathrm{Na}$ medida em que foi surgindo a sociedade democrática, segundo Taylor, a honra, que expressava o reconhecimento dado segundo o lugar ocupado e os papéis desempenhados, deu lugar ao reconhecimento da igual dignidade de todos. Paralelamente desenvolveu-se a noção de identidade individual, que veio acompanhada do ideal de autenticidade, de ser fiel a si mesmo. Em Rousseau, Taylor encontra o autor que teria sido pioneiro em formular essa nova visão. Essa autenticidade está intimamente ligada a uma mudança na origem da própria noção ética, descrita como uma voz que vem do interior e que mostraria ao indivíduo como viver. A capacidade de cada um, de criar e perseguir seu próprio modo de vida, torna cada indivíduo original e coloca-o diante da questão da fidelidade a esse projeto. Essa concepção de originalidade e do ideal de autenticidade, que em Rousseau estava focado no indivíduo, Herder estendeu para além do nível individual, referindo-se também a povos com sua cultura. Nessa concepção, cada um e todos são convocados a descobrir sua própria maneira original de ser e a serem fiéis a si próprios.

Mas como a identidade seria moldada também pelo reconhecimento por parte de outros, estaria colocada a exigência de que tanto os indivíduos como os povos fossem reconhecidos em sua originalidade e tivessem asseguradas condições de permanecerem autênticos, fiéis a sua própria cultura. Para descrever a relação entre formação da originalidade e o reconhecimento, Taylor recorre à figura do outro significativo, desenvolvida por Mead. Segundo essa concepção, as pessoas estabeleceriam ao longo de toda sua vida interações que levam à reformulação de sentidos, objetivos e cursos de ações. Assim, a identidade do indivíduo ou povo seria formada em diálogo com aquilo que os outros significativos desejam ver neles - uma negociação constante feita com o outro ao longo de toda a vida.

Para chegar ao seu objetivo, que é tratar da luta política por reconhecimento e sobrevivência de identidades culturais coletivas, Taylor introduz uma diferenciação adicional. Segundo ele, há uma esfera íntima, na qual a identidade é formada e reconhecida em diálogo e em luta com outros significativos, e uma esfera pública, na qual se desenvolvem políticas de reconhecimento. É a essa última que a atenção do autor se volta principalmente. 
Precisamente na esfera pública, nas políticas de reconhecimento baseadas na noção de respeito igual, o autor vê dois movimentos em tensão. De um lado, uma política universalista, que coloca a ênfase na igualdade, na dignidade inerente a cada pessoa humana, e assegura direitos iguais de cidadania a todos. De outro, uma política com maior vinculação com a noção de identidade, que coloca sua ênfase na diferença. Uma se concentra naquilo que "é o mesmo em todos" os seres humanos, mas com isso os homogeniza e nega sua identidade; a outra vê a necessidade de se reconhecer e até mesmo promover a particularidade, admitindo certo grau de restrição às liberdades individuais, certa discriminação (Taylor, 2000, p. 254).

A primeira dessas orientações, que o autor denomina "liberalismo da dignidade igual" (ibid.), não é totalmente cega às diferenças, mas supõe a existência de alguns princípios universais que estariam acima das particularidades culturais. Vários autores de orientação liberal, como Rawls, Dworkin e Habermas, acolheram em suas teorias justificativas para políticas de reconhecimento da diferença na forma de ações afirmativas, dando assim uma formulação teórica a reivindicações feitas por diversos movimentos sociais. Na visão de Taylor, porém, essas reflexões teóricas permaneceriam excessivamente apegados a ideais monológicos, e, o que nesse contexto é mais importante, as políticas correlatas tão somente buscariam compensar desigualdades temporárias, mas acabariam resultando em homogeneização. Elas ajudariam os diferentes à condição de esses se tornem praticamente iguais. Aquele conjunto de princípios considerados universais não seria neutro, mas apenas parte de uma cultura predominante.

No entanto, Taylor (2000, p. 260) reluta em aderir ao movimento dos que propugnam radicalmente pela valorização das diferenças; considera que as políticas que defendem implicam num fechamento etnocêntrico em relação ao outro. Sua opção é, antes, a de estabelecer um diálogo com os defensores do reconhecimento de igual dignidade, questionando sua visão de que no liberalismo seja inaceitável "levar em conta diferentes metas coletivas". Em sua visão, a perspectiva na qual os autores que se focam centralmente na dignidade igual trabalham as questões da diferença está equivocada. Ao privilegiarem a perspectiva da justiça, as políticas de reconhecimento teriam como horizonte a superação da diferença - enquanto o objetivo pelo qual se engaja Taylor é o da sobrevivência autêntica de identidades culturais específicas.

A luta por políticas de reconhecimento e medidas restritivas da liberdade individual seriam justificadas para esse autor sempre quando destinadas a fomentar modos de vida específicos e, inclusive, a sobrevivência de grupos sociais que sejam seus portadores. As políticas defendidas no Quebéc e 
apoiadas por Taylor ultrapassavam em muito a pretensão de "assegurar-se de que haja uma comunidade de pessoas no futuro que deseja aproveitar a oportunidade de usar a língua francesa"; muito mais que preservar condições formais de disputas política, ao forçar a escolarização na língua francesa, estavam ativamente buscando "criar membros da comunidade" (Taylor, 2000, p. 264).

O autor faz uma distinção na leitura do liberalismo, para diferenciar sua posição em relação aos interlocutores: numa leitura, seria considerado inaceitável reconhecer identidades culturais específicas e desenvolver políticas de modo diferenciado segundo o contexto para salvaguardar as metas coletivas de seus portadores, como a de assegurar sua sobrevivência. Suas características seriam que ela: "a) insiste na aplicação uniforme das regras que definem esses direitos [ao respeito igual], sem exceção, e b) suspeita de metas coletivas" (Taylor, 2000, p. 265). Com isso, não seria possível assegurar aquilo que é chave para Taylor: garantir a sobrevivência cultural do grupo. Por isso, ele defende a possibilidade de que, dentro de uma visão liberal, seja possível uma outra interpretação, que estabeleça uma outra relação entre aplicação uniforme da norma e respeito a metas coletivas, e não seja tão homogeneizante. Sociedades que se pautam por essa segunda variante do liberalismo fariam uma defesa invariante de certos direitos fundamentais, mas "se dispõem a sopesar a importância de certas formas de tratamento uniforme com relação à importância da sobrevivência cultural" (ibid., p. 266). O liberalismo, nessa visão, não seria neutro em relação às formas culturais e aos objetivos coletivos de vida, mas seria "um credo em luta", em disputa com outros. As políticas defendidas pelos francófonos no Canadá expressariam para ele essa visão alternativa do liberalismo numa situação concreta.

Na resposta que Habermas dá a Taylor, ele contesta tanto a necessidade de se distinguir entre duas leituras do liberalismo para poder acolher a pluralidade cultural, como também a possibilidade de que, num estado democrático de direito, a sobrevivência intacta de determinadas identidades coletivas possa ser assegurada pela via legal. Em sua visão, a luta pelo reconhecimento não precisa, e, a rigor, nem deveria passar pela reivindicação de proteção de formas específicas de vida, mas pela constituição de uma esfera pública na qual as diferentes formas de vida podem ser defendidas argumentativamente e os indivíduos podem compor livremente o leque de suas adesões "identitárias".

Ao desenvolver seu argumento, Habermas primeiro destaca que, em sua visão, a ordem jurídica moderna tem como base direitos individuais, subjetivos. As constituições são entendidas como um projeto histórico a ser cumprido a cada geração. Como esse projeto será cumprido, isso resultará de disputas 
levadas a efeito na arena política, mediante as quais as novas realidades contextuais da coletividade são acolhidas. Mesmo naqueles casos em que essa reinterpretação da ordem jurídica acolheu bens tidos como coletivos, a distribuição ou a fruição desses bens seria individualizada, preservando intacta a base dessa forma de organização social, fundamentada em direitos subjetivos individualizados.

Para a pergunta, se a luta por identidades coletivas seria compatível com direitos subjetivos, a resposta de Habermas é inequivocamente sim. Ele faz uma distinção entre duas formas de reconhecimento público que seriam hoje amplamente aceitas: o respeito à identidade inconfundível de cada indivíduo e o respeito pelas formas de ação, práticas e visões de mundo de determinados grupos considerados desprivilegiados. Se, como queria Kant, o direito a liberdades subjetivas iguais for o único e original direito humano, a segunda exigência seria uma decorrência da primeira. Uma ordem jurídica seria eticamente neutra, e sob certas condições também justa, precisamente ao permitir que dentro dela cada qual poderia escolher e buscar realizar sua própria concepção do que seja bom. Enquanto na visão de Taylor haveria a possibilidade de as duas formas de respeito entrarem em colisão, sem que houvesse uma definição prévia sobre a questão à qual dar precedência, na interpretação de Habermas não haveria um choque entre elas. Mais que isso, a reivindicação subscrita por Taylor, de que haja não apenas políticas destinadas a garantir a sobrevivência de formas culturais de determinados grupos, mas também políticas empenhadas em gerar futuros integrantes desse grupo, é tida por Habermas como muito mais que apenas uma nova interpretação do liberalismo; ele vê nela um ataque à compreensão individualista do direito moderno (Habermas, 2002, p. 231-234).

Com o intuito de fundamentar a tese da compatibilidade entre direitos subjetivos e luta por identidades coletivas, e, por conseguinte, opor-se à introdução formal de direitos coletivos na atual ordem jurídica, Habermas desenvolve uma sequência de argumentos, começando pela questão da autonomia. Além de garantir liberdades subjetivas de ação igual para todos os seus membros na forma de direitos fundamentais e da possibilidade de divergências de interpretação desses direitos serem decididas em tribunais, para Habermas uma ordem jurídica precisa permitir que seus membros possam compreender-se eles próprios como co-autores das leis a que estão sujeitos. Essa segunda dimensão seria uma concatenação lógica interna e necessária que expressaria a equiprocedência da autonomia privada e pública. Os cidadãos seriam autônomos na medida em que não apenas desfrutem privadamente de seus direitos individuais subjetivos, mas participem também da decisão 
sobre a definição e o tratamento a ser dado em sua sociedade às igualdades e às diferenças. A luta do movimento feminista serve-lhe de exemplo para mostrar como a ampliação de direitos subjetivos, que se destinam a "garantir às mulheres uma organização particular e autônoma da própria vida", mantém truncada a autonomia se as próprias pessoas afetadas não puderem "articular e fundamentar, em discussões públicas, os aspectos relevantes para o tratamento igualitário ou desigual de casos típicos" (Habermas, 2002, p. 237).

A questão da legitimidade das lutas por reconhecimento é igualmente colocada em discussão por Habermas. Feminismo, multiculturalismo, nacionalismo e luta contra a herança do colonialismo são diferenciados como formas específicas de luta por reconhecimento; da relação estabelecida nessa luta, tanto desafiantes como desafiados seriam levados a modificar aspectos de sua identidade coletiva. As decisões políticas a que essas lutas conduzem tornam-se efetivas em sociedades complexas mediante a positivação. A forma do direito que as decisões normativas prévias tomadas no plano político assumem é definida por Habermas (2002, p. 242) como uma estrutura artificial formal, individualista, coercitiva, positivada e escrita por via procedimental. Esse direito só pode regrar o comportamento das pessoas, não suas motivações - não obstante isso, a subsistência de uma ordem jurídica no tempo depende também de que ela seja aceita como legítima, que ela assegure a todos os cidadãos por igual a autonomia.

$\mathrm{Na}$ conexão entre a luta política e a positivação de direitos, Habermas vê a base para poder afirmar que a ordem jurídica não seja eticamente neutra, mas expresse em parte também uma forma de vida em particular. Disso o autor deriva outro argumento em favor da compatibilidade entre direitos subjetivos e lutas por reconhecimento de formas coletivas de vida, e com ele explicita sua concepção de como identidades são defendidas e preservadas. Como a disputa política pela interpretação dos direitos na democracia se dá mediante discursos na esfera pública, para Habermas concomitantemente ocorre também uma maior consciência dos cidadãos de si próprios. A incorporação de novos grupos, seja por efeito de migrações, de mudanças nas fronteiras ou outras mais, está entre os fatores que tornam a identidade algo dinâmico, em constante adaptação aos novos contextos.

Identidades e culturas nessa concepção só se mantêm vivas enquanto envolvidas em autotransformação, enquanto em permanente processo de revisão, no qual alguns componentes tradicionais podem ser abandonados e substituídos. Isso não valeria apenas para a relação de umas culturas com as outras, mas também para aquela dos indivíduos com sua herança cultural, pois as culturas só seriam capazes de manter vivas suas tradições e formas de vida se 
e enquanto conseguirem vincular os seus integrantes a elas. Habermas vale-se da imagem da biologia para assegurar que essa sobrevivência de culturas não pode ser confundida com a preservação intacta de espécies. Objetivos radicais de preservação podem ser vistos, por exemplo, nos fundamentalismos, que se recusam a dialogar e reivindicam para si exclusividade para certas formas de vida, sem perceberem que aquilo de substantivo que buscam preservar a rigor já não subsiste.

Com isso Habermas pode chegar ao seu conjunto argumentativo mais abrangente para a defesa de sua tese nessa discussão: a distinção entre integração política e integração ética como sendo respectivamente aquela que apreende os cidadãos do estado de forma equitativa e aquela que acolhe grupos e subculturas com suas identidades coletivas (Habermas, 2002, p. 253ss). A integração de imigrantes serve-lhe de exemplo para abordar as múltiplas facetas desse processo. $\mathrm{O}$ imigrante precisa aceitar uma socialização política na qual a sociedade que o acolhe já tem sua compreensão ética e sua cultura política historicamente formadas e para cuja transformação ele só no longo prazo poderá contribuir; já a exigência de uma socialização cultural, que implicaria na adesão ao modo concreto de vida local na forma de integração ética, não seria pertinente. Habermas está convencido que o estado democrático de direito "pode garantir a identidade da república [...] haja vista estar firmada sobre os princípios constitucionais ancorados na cultura política [...]. De acordo com isso, só é preciso esperar dos imigrantes que eles se disponham a arraigar-se na cultura política de sua nova pátria, sem que por isso tenham de renunciar à forma de vida cultural de sua origem" (Habermas, 2002, p. 258).

Assim, para Habermas, cada indivíduo e cada grupo dentro do estado democrático de direito tem assegurada a sua integração pelo consenso mínimo sobreposto, no sentido dado por Rawls; no patriotismo constitucional os cidadãos do estado se agregam em torno de um projeto comum, no qual, ao mesmo tempo, podem defender publicamente a validade do seu modo específico de vida e se expõem aos questionamentos que seus concidadãos fazem a eles, e que exigem uma fundamentação racional. Por meio dessa integração em dois níveis - política e ética -, direitos subjetivos fundamentais assegurados a todos são compatíveis com a luta por identidades coletivas; não há entre elas colisão porquanto a primeira é vista como pressuposto para a segunda.

Nem Taylor nem Habermas concebem a identidade como estática; mas esses autores diferem na visão sobre como se estabelece sua reafirmação e renovação em processos intersubjetivos. Em Taylor, a ênfase é dada a um diálogo íntimo que o indivíduo faz face às propostas culturais dadas; nesse diálogo, os outros significativos são uma referência subjetivo-afetiva decisiva. Já em 
Habermas, cultura e identidade estão expostas a uma disputa por preferência e legitimação através de argumentação racional numa arena, a esfera pública. Para Taylor, há uma herança cultural, fortemente vinculada ao idioma, que é preservada na medida que novas gerações dela se apropriam, e elas o fazem ao longo de toda sua vida em contextos em que podem espelhar-se em pessoas que lhes sejam importantes como portadoras da mesma herança. Habermas vê a cultura mais próxima de um conjunto de estruturas disposicionais que se fazem presentes quando indivíduos discutem publicamente suas respectivas concepções de uma vida boa, de uma vida bem sucedida; essas concepções são para ele o foco da questão: o estado democrático de direito em sua visão precisa assegurar condições para que as diferentes concepções do bem viver possam ser reafirmadas e legitimadas publicamente mediante argumentação racional.

\section{Reconhecimento como condição da autonomia}

Nancy Fraser (2006a; 2006b) e Axel Honneth (2006a; 2006b) fizeram um debate sobre questões do reconhecimento, que teve ampla repercussão pública. Ele iniciou com um texto em que Fraser se refere à proposta de uma teoria do reconhecimento publicada pouco antes por Honneth (2003) e teve seguimento com as respectivas réplicas e a tréplica de Honneth. Frequentemente o debate é abordado na perspectiva da pergunta pela relação entre redistribuição ou reconhecimento; é a pergunta-título do livro que acolhe o debate. Para ambos os autores, o reconhecimento expressa as bases normativas das reivindicações políticas atuais e ocupa um lugar que há algumas décadas era ocupado pelas reivindicações por redistribuição de recursos econômicos. Reconhecimento e redistribuição são vistos como parte de um conceito abrangente de justiça, mas os autores divergem sobre a relação entre os dois tipos de reivindicação: enquanto Fraser os vê como duas dimensões fundamentais da justiça, irredutíveis uma a outra, Honneth considera o reconhecimento como uma gramática com a qual se expressam lutas políticas atuais, inclusive aquelas por redistribuição.

Fraser parte da convicção de que haja dois tipos distintos de reivindicação por justiça, irredutíveis entre si: uma redistribuição mais justa dos recursos e da riqueza, e reconhecimento da diferença, de modo a que a integração social não sacrifique o respeito igual. Sua percepção é de que na atualidade estaria havendo um deslocamento das reivindicações de cunho redistributivo a uma prioridade dada às questões de reconhecimento. Nas lutas que movimentos sociais e atores políticos da sociedade civil travam, eles se orientam por um conjunto de concepções sobre as causas e possíveis soluções para as injustiças, 
que Fraser denomina paradigmas populares de justiça. Equivocadamente, no entanto, estaria ocorrendo por vezes uma polarização entre a luta por uma política de redistribuição ou de classe por um lado e aquela por uma política de reconhecimento ou de identidade por outro. E entre essas alternativas, o paradigma da redistribuição, que foi predominante no período em que o estado de bem-estar se desenvolveu em direção ao auge de sua aceitação, vai sendo preterido e o paradigma do reconhecimento assume seu lugar.

Para mostrar como se dá essa polarização, Fraser (2006a, p. 22-25) descreve quatro dimensões desses paradigmas de justiça e modo como elas são definidas por cada um. No paradigma da redistribuição, a injustiça é vista como parte da estrutura econômica da sociedade, e o remédio para superá-la seria uma redistribuição da renda, do patrimônio, das decisões econômicas ou mudanças na divisão do trabalho. Quem sofre a injustiça, nessa perspectiva, são classes ou grupos similares definidos economicamente e, mais recentemente, coletividades étnicas ou de imigrantes. As diferenças que os distinguem são vistas como socialmente construídas e não como intrínsecas, e a luta política se destina a abolir e não a reconhecer essas diferenças.

No paradigma do reconhecimento, por sua parte, a injustiça é vista como parte dos padrões sociais de representação, interpretação e comunicação, e requer mudança cultural ou simbólica que reavalie as identidades e os produtos culturais, valorizando grupos por ora discriminados e questionando os padrões dominantes. A injustiça afeta grupos de status, a quem se concede menor respeito, estima e prestígio. Os diferenciais que delimitam o grupo podem tanto ser qualidades inerentes a ele, e nesse caso a luta política será por reavaliar e celebrar essas características, ou podem ser construções sociais discriminantes, formadoras de hierarquias, e devem ser desconstruídas e superadas.

Para a autora, no entanto, a construção de uma polarização em torno desses paradigmas é uma falsa antítese, porquanto em sua concepção a injustiça é vista como um espectro, cujos extremos seriam formados por esses dois tipos ideais; no cotidiano, no entanto, a injustiça assumiria formas mistas em que, em graus diversos, se mesclariam má distribuição e reconhecimento errôneo ou negado. Face a essa constatação, Fraser defende a tese de que a justiça exige tanto a redistribuição como o reconhecimento; sua proposta é encontrar um conceito de justiça capaz de integrar as duas dimensões, preservando clareza sobre a relativa independência de cada uma. Assim seria possível englobar conceitualmente não só as situações de injustiça localizadas nos extremos do espectro, que são relativamente fáceis de diagnosticar, porém infrequentes, senão também aquelas que mesclam em proporções distintas das duas dimensões. 
A questão que se coloca, então, para Fraser é como integrar consistentemente num conceito ampliado de justiça as dimensões da redistribuição e do reconhecimento de modo que seja possível distinguir entre reivindicações justificadas e injustificadas. Sua resposta será colocar o que ela denomina de paridade participativa como o núcleo normativo de sua concepção de justiça, como o fundamento sobre o qual erige sua proposta teórica. Para ela, "a justiça exige alguns acordos sociais que permitem que todos os membros (adultos) da sociedade interatuem em pé de igualdade" (Fraser, 2006a, p. 42). Duas condições se fazem necessárias para tornar essa participação possível: uma objetiva, que são recursos naturais que garantam a independência da "voz", e outra subjetiva, que são padrões culturais institucionalizados que garantam oportunidades iguais para conseguir a estima social.

Isso leva a autora a insistir que o reconhecimento errôneo seja uma violação da justiça, porque subordina e impede a participação como igual na vida social e resulta em relações de subordinação. Sua leitura da proposta de Honneth é que esse autor reduziria a questão do reconhecimento a um problema de realização pessoal, ao passo que ela, ao colocar o reconhecimento como uma questão de justiça, insere-o na problemática do status social. Assim pretende conseguir mostrar que as reivindicações de reconhecimento são moralmente vinculantes e se inserem no centro das relações sociais, retirandoas da esfera individual.

As reivindicações de reconhecimento podem, então, ser distinguidas como justificadas se elas se voltam contra normas atuais que negam as condições objetivas ou subjetivas da paridade participativa e se as novas práticas almejadas não negarão essas condições, nem dentro nem fora do grupo. O meio para realizar essa distinção para a autora são discussões em processos democráticos de debate público. Para a autora, é importante levar sempre em consideração a perspectiva da teoria social que mostra como economia e cultura são esferas diferenciadas mas interpenetradas e que mudanças numa delas têm efeitos não previstos na outra.

Sob a ótica da teoria política, a autora destaca a necessidade de instituições que garantam a paridade participativa, que superem a injustiça e

1 Embora não explicitado, a autora se refere à contraposição voice versus exit, colocada por Hirschman (1978) para tipificar a relação do cliente insatisfeito com seu fornecedor: exit seria a postura econômica daquele que busca alternativas em outras fontes, enquanto voice seria a postura política daquele que se manifesta na expectativa de provocar mudança. Há diversas dificuldades em aplicar essa tipificação à vida política, porquanto o cidadão, diferente do consumidor, tem dificuldades muito peculiares na opção exit. Muitos autores, mesmo assim, consideram que a opção voice da relação de consumo pode ser usada analogamente na vida política. 
integrem as duas dimensões da justiça. O foco de sua atenção são reformas que possam servir como remédio para a injustiça e que iniciem pelo combate aos sintomas, mas provoquem transformações capazes de atingir também as causas da injustiça. Eliminar os impedimento para a paridade participativa para ela implica em realizar um conjunto de reformas que ela define como conjugação de afirmação e transformação: a primeira consistiria em minimizar os resultados da injustiça já institucionalizada, e a segunda, em trabalhar com sistematicidade na superação das causas (Fraser, 2006a, p. 71-73).

Para toda a crítica que Fraser faz a Honneth, é central sua convicção de que o foco da teoria desse autor sejam políticas de identidade, de cunho comunitarista, similares àquelas defendidas por Taylor, e que políticas culturais, de identidade, seriam inadequadas para dar conta da distribuição dos recursos e riquezas. Esta interpretação da teoria de Axel Honneth está, porém, totalmente equivocada. O próprio autor deixa bem claro em sua resposta que sua teoria parte de fundamentos totalmente diferentes. A crítica de Fraser, portanto, não atinge a teoria do reconhecimento de Honneth, mas sim uma interpretação dela que o autor considera equivocada, como ele frisa em sua resposta. Por fim, igualmente central para a autora é a convicção, que no fundo é retirada de uma interpretação descontextualizada e simplificada das teorias de Habermas e de Rawls, de que a participação em condições de igualdade seja um critério normativo dado, capaz de orientar a formação de juízos e práticas sociais concordes com uma concepção ampla de justiça.

Ao responder aos questionamentos de Fraser, Honneth enfatiza que seu ponto de partida é a preocupação de encontrar uma linguagem teórica que se adapte melhor para reconstruir consistentemente e para justificar as demandas políticas atuais na perspectiva de uma teoria crítica. Ele está convencido de que ao invés de justapor reivindicações de reconhecimento e de redistribuição, como quer Fraser, uma teoria do reconhecimento suficientemente diferenciada pode expressar melhor o vínculo existente entre "causas sociais dos sentimento generalizados de injustiça e os objetivos normativos dos movimentos emancipadores" (2006a, p. 91).

Essa teoria em sua visão será capaz de expressar o sofrimento e as injustiças sociais independentemente de elas estarem ou não articuladas politicamente por movimentos sociais na esfera pública, e de fornecer os critérios normativos que orientam a crítica. Assim, segundo esse autor, se evitaria o risco de deixar submersas e ocultas para a teoria todas aquelas expressões cotidianas de sofrimento e injustiça que não foram suficientemente articuladas para conseguirem passar pelo filtro da esfera pública. Segundo sua convicção, não podem ser os movimentos sociais que informam a teoria 
onde ela deve buscar seu objeto, como lhe parece estar sendo sugerido por Fraser, mas é a teoria que fornece os critérios normativos com base nos quais é possível analisar situações concretas. Em suas palavras: "para poder investigar de alguma maneira as formas de descontentamento e sofrimento sociais é necessário alcançar uma compreensão prévia conceitual das expectativas normativas que devemos supor com respeito aos membros da sociedade" (Honneth, 2006a, p. 101).

Honneth recorda que na teoria social há muito tempo já havia estudos apontando para a busca de reconhecimento como uma motivação nas lutas sociais, mas defende que "o que faz falta é uma mudança conceitual básica em direção às premissas normativas de uma teoria do reconhecimento que situe o núcleo central de todas as experiências de injustiça na retirada do reconhecimento social, nos fenômenos de humilhação e falta de respeito" (ibid., p. 107). Para ele, portanto, não procede a tese defendida por Fraser, segundo a qual teria havido uma mudança de foco nas lutas sociais de objetivos socioeconômicos para lutas na esfera cultural. Honneth defende que, pelo menos no que diz respeito à sua proposta teórica, a mudança se expressa na busca de uma nova linguagem teórica, capaz de expressar mais precisamente anseios já presentes há muito tempo.

O núcleo da argumentação teórica de Honneth parte da constatação de que na sociedade burguesa capitalista teria havido um desenvolvimento social e moral que resultou numa diferenciação gradativa de três esferas de reconhecimento - do amor, da lei e do desempenho (Sobottka e Saavedra, 2009) -, levando a que os membros da sociedade passassem a poder contar com o reconhecimento recíproco específico a cada uma delas e, por conseguinte, a experimentar o valor duradouro de suas capacidades e a ampliar sua individualidade. Não só se desenvolveram as relações afetivas e intrafamiliares que evidenciaram um tipo específico de necessidade e de interação social orientada pelo afeto e a atenção, mas a antiga ordem hierárquica baseada na honra se desdobra numa ordem jurídica igualitária em que o indivíduo é reconhecido como portador de direitos subjetivos, por um lado, e uma esfera do mérito em que o indivíduo conquista reconhecimento pelo desempenho individual, por outro.

\section{Reconhecimento: de conceito marginal a conceito chave na filosofia e teoria social contemporâneas}

Os debates analisados explicitam a polissemia do conceito de reconhecimento, que serve de base para o desenvolvimento da teoria do reco- 
nhecimento de Paul Ricouer. Na verdade, exatamente essa imprecisão no desenvolvimento do conceito é utilizada pelo autor como justificativa para a elaboração da "primeira" teoria do reconhecimento da história da filosofia: "A pesquisa foi suscitada por um sentimento de perplexidade concernente ao estatuto semântico do próprio termo 'reconhecimento' no plano do discurso filosófico. É fato que não existe uma teoria do reconhecimento digna desse nome ao modo como há uma ou várias teorias do reconhecimento. Ora essa lacuna surpreendente contrasta com a espécie de coerência que permite que a palavra 'reconhecimento' figure em um dicionário como uma unidade lexical única a despeito da multiplicidade que essa unidade lexical envolve, das acepções atestadas na comunidade lingüística reunida pela própria língua natural, no caso a língua francesa" (Ricoeur, 2006, p. 9). Ele procura, portanto, “conceder à série de ocorrências filosóficas conhecidas da palavra 'reconhecimento' a coerência de uma polissemia regrada, digna de oferecer a réplica à do plano lexical (Ricoeur, 2006, p. 10).

Ricouer analisa o conceito de reconhecimento a partir da perspectiva da língua francesa, que, como em outras línguas, trabalha com um conceito polissêmico da palavra reconhecimento, diferentemente, da língua alemã, de cuja perspectiva os filósofos mais conhecidos da teoria do reconhecimento, como Hegel e Honneth, analisam o conceito. Nesse sentido, o prefácio da edição alemã do livro é bem instrutivo e interessante: "Esta última grande pesquisas filosófica de Paul Ricoeur é dedicada ao reconhecimento. Não obstante, o leitor precisa esperar pacientemente até o terceiro estudo, até que este conceito esteja no centro da análise, dado que 'reconhecimento' é, em francês, apenas um dos tantos significados de reconnaissance" (Bokelman e Heber-Schärer, 2006, p. 9). Este prefácio mostra com toda a clareza como a língua, a partir da qual se trata a teoria do reconhecimento, funciona como uma espécie de ponto cego. Encarando-se a discussão a partir do contexto alemão, o conceito de reconhecimento tende a ser analisado apenas a partir do seu caráter intersubjetivo. Analisando o conceito a partir de uma língua latina, esse conceito parecer ter uma abrangência muito maior, dado que, nas línguas latinas, a palavra reconhecimento pode significar "identificar", "re-conhecer", ou seja: conhecer de novo, ou mais precisamente: chamar à memória uma imagem novamente, além do clássico reconhecimento intersubjetivo ou mútuo. Ricoeur vale-se dessa característica da língua francesa para associa o conceito a três problemáticas fundamentais da filosofia: 1) reconhecimento como identificação (Descartes e Kant); 2) o reconhecimento de algo e o reconhecer-se a si mesmo (Bergson) e 3) o reconhecimento mútuo ou intersubjetivo (Hobbes, Hegel e Honneth). 
Nesse sentido, a partir da perspectiva de Ricoeur, o caráter social e político do conceito de reconhecimento, tão presente na discussão de Taylor, Habermas, Fraser e Honneth, perde a centralidade, passando a ter um valor apenas indireto. A teoria do reconhecimento passa a ser vista como uma teoria do conhecimento, uma epistemologia. Na verdade, para Ricouer, a teoria do reconhecimento não seria nem uma teoria, mas uma "dinâmica que guia, em primeiro lugar, a promoção do reconhecimento-identificação, em segundo lugar, a transição que conduz da identificação de algo em geral ao reconhecimento por si mesmas de entidades especificadas pela ipseidade e, por fim, do reconhecimento de si mesmo ao reconhecimento mútuo, até a última equação entre reconhecimento e gratidão, que a língua francesa é uma das raras a honrar (Ricoeur, 2006, p. 10).

Ricouer critica a teoria do reconhecimento de Honneth, porque ele concentra seu foco em apenas uma dimensão do conceito, ou seja, que ele trilha apenas um caminho do reconhecimento. Além disso, quando Ricouer rediscute os fundamentos da teoria do reconhecimento de Honneth (Ricoeur, 2006, p. 201-232), ele chega à conclusão que a teoria de Honneth se concentra apenas em explicar a motivação moral dos conflitos e lutas sociais deixando de lado o fato de que "a certeza que acompanha os estados de paz oferece antes uma confirmação de que a motivação social das lutas por reconhecimento não é ilusória" (Ricoeur, 2006, p. 232). A alternativa para a idéia de luta no processo de reconhecimento mútuo teria de ser procurada, portanto, segundo Ricoeur, "nas experiências pacificadas de reconhecimento mútuo, que se baseiam em mediações simbólicas subtraídas tanto da ordem jurídica como da ordem das trocas mercantis; o caráter excepcional dessas experiências, longe de desqualificá-las, salienta sua gravidade, e com isso assegura sua força de irradiação e de irrigação no próprio âmago das transações marcadas pela chancela da luta (Ricoeur, 2006, p. 233).

Com essa alternativa, que representa, aparentemente, uma mudança singela, a dimensão teórico-social da teoria do reconhecimento se torna metafísica. Para esse tipo de teoria metafísica do reconhecimento, as pesquisas empíricas e sociais perdem interesse e a dinâmica do reconhecimento não é mais analisada em conjunto com uma teoria normativa da sociedade. Assim, a separação entre ser e dever-ser se enraíza definitivamente no núcleo da teoria do reconhecimento. Ao mesmo tempo, porém, se abrem novos caminhos do reconhecimento, que até então não haviam sido considerados e muito menos seguidos. Se a teoria do reconhecimento de Paul Ricouer, porém, conseguiu englobar todos os possíveis caminhos do reconhecimento, somente o futuro dirá. Sua teoria, no entanto, abriu uma série de novas perspectivas que precisam ser 
melhor exploradas, pois, como se pode ver ao longo do presente artigo, não se ganha muito quando se tenta reduzir o fenômeno do reconhecimento a somente uma de suas dimensões. A determinação do conceito de reconhecimento nada mais é do que a sua própria história. Desvelá-la, esta é sim a tarefa do teórico do reconhecimento.

\section{Referências}

BOKELMANN, U.; HEBER-SCHÄRER, B. Vorwort der Übersetzerinnen. In: RICOEUR, Paul. Wege der Anerkennung. Frankfurt am Main: Suhrkamp, 2006. p. 9-11.

FRASER, N. La justicia social en la era de la política de la identidad: redistribución, reconocimiento y participación. In: FRASER, N.; HONNETH, A. ¿Redistribución o reconocimiento? A Coruña: Paideia, 2006a. p. 17-88.

. Una deformación que hace imposible el reconocimiento: réplica a Axel Honneth. In: FRASER, N.; HONNETH, A. ¿Redistribución o reconocimiento? A Coruña: Paideia, 2006b. p. 149-175.

HABERMAS, Jürgen. A luta por reconhecimento no estado democrático de direito. In: . A inclusão do outro. São Paulo: Loyola, 2002.

HIRSCHMAN, Albert O. Exit, voice, and loyalty: responses to decline in firms, organizations, and states. Cambridge: Harvard University Press, 1978.

HONNETH, Axel. Luta por reconhecimento: a gramática moral dos conflitos sociais. São Paulo: Ed. 34, 2003.

. Redistribución como reconocimiento: respuesta a Nancy Fraser. In: FRASER, N.; HONNETH, A. ¿Redistribución o reconocimiento? A Coruña: Paideia, 2006a. p. 89-148.

. La cuestión del reconocimiento: réplica a la réplica. In: FRASER, N.; HONNETH, A. ¿Redistribución o reconocimiento? A Coruña: Paideia, 2006b. p. 176-196.

RICOEUR, Paul. Percurso do reconhecimento. São Paulo: Loyola, 2006.

SOBOTTKA, Emil A.; SAAVEDRA, Giovani A. Die Debatte um den Begriff der Anerkennung. Soziale Passagen, Wiesbaden, v. 1, n. 2, p. 193-207, 2009.

TAYLOR, Charles. A política do reconhecimento. In: . Argumentos filosóficos.

São Paulo: Loyola, 2000. p. 241-274. 